\title{
Impact of medication and psychological behaviour assessment by community pharmacists in type 2 diabetes mellitus patients after hospital stay
}

\author{
Sudhir Singh Gangwar ${ }^{1}$, N. Monisha ${ }^{2}$, Jainaf Nachiya ${ }^{2}$, Kanchana Narasingarao ${ }^{3}$, \\ Parimalakrishnan. $\mathrm{S}^{2}$ and Seo Pratap Singh ${ }^{4}$
}

1. Department of Pharmaceutical Sciences, GSVM Medical College, Kanpur, Uttar Pradesh, India.

2. Department of Pharmacy, Annamalai University, Annamalai Nagar, Tamil Nadu, India.

3. Andhra Yuvathi Mandali, School of Pharmacy, Barkatpura, Hyderabad, Andhra Pradesh.

4. Department of Pharmacology, GSVM Medical College, Kanpur, Uttar Pradesh, India.

\begin{abstract}
Drug related problem (DRPs) is a key factor which will affect the outcome of therapy and safety. The aim of the present study is to assess the DRPs in T2DM patients and psychological aspects of patients by community pharmacists to observe the rate of DRP. Prospective randomized controlled intervention study involved T2DM patients and conducted in two community pharmacies at Kanpur from January 2012 to December 2012. The assessment of DRPs was based on the PCNE. Changes in $\mathrm{HBA}_{1 \mathrm{C}}$, LDL, BP, foot examinations, changes medical and medication utilization were studied. Using as control group, received usual care, and interventional group provided, intervened with use of the STG. Researcher provided the knowledge to community pharmacists and patients. Baseline and interventional data were collected at 0,3,6,9 and 12 months. Over 12 month study, participants' average $\mathrm{HBA}_{1 \mathrm{C}}$ reduced from $8.9 \%$ at initial visit to $7.5 \%$. During this time, the eye examination rate was raised from $31 \%$ to $48 \%$, and the foot examination rate was raised from $35 \%$ to $50 \%$. It may be concluded that the intervention of pharmacists showed very less significant influence on any of the intermediate health outcomes in T2DM.
\end{abstract}

Keywords: Type 2 Diabetes Mellitus, Drug related problems, PCNE classification, Medication review, Psychological behavior.

DOI:http://dx.doi.org/10.4314/ahs.v14i3.7

\section{Introduction}

The type 2 diabetes mellitus (T2DM) is a chronic metabolic disorder characterised by defects in insulin secretion and/or insulin resistance. It forms part of a cluster of cardiovascular risk factors seen in at higher rates in patients with T2DM, which is characterised as the metabolic syndrome. That includes central obesity, hypertension and/or dyslipidaemia etc. (Carrera Boada. CA and Martínez-Moreno. JM, 2013) India is the leading country in the world with the greatest number of diabetes patients. According to the International Diabetes Federation (IDF) atlas 2012, the cases recorded for T2DM were 63,013.87 (in 1000s), diabetic related deaths constituted for 1,013,057 and undiagnosedcases of T2DM were 32,184.34 (in 1000s). (Whiting. DR et al 2011 and Anjana RM et al 2011) Hypertension is the

\section{Corresponding Author:}

Parimalakrishnan. S,

Department of Pharmacy,

Annamalai University, Annamalai

Nagar-608002. India.

E-mail: gsvmssgangwar@rediffmail.com. most common co morbidity in T2DM patients, with a prevalence rate up to two-thirds of the global population. Hypertension triggers the risk of cardiovascular disease in T2DM patients and also enhances the possibility of developing microvascular complications such as diabetic nephropathy and retinopathy. (Paul P. Dobesh, 2006)

Patients with any illness or disease along with another precipitating co-morbidity condition often receive multiple medications which often lead to the occurrence of drug-related problems (DRPs). (Zaman Huri and Fun Wee, 2013) A DRP is an event or circumstance involving drug therapy that actually or potentially interferes with desired health outcomes. There is a high prevalence rate of DRPs that has been observed in T2DM patients. DRPs may lead to additional complications that may lead to significant morbidity or mortality, prolonged hospitalization, and increased health care expenditure. Several problems and causes of DRPs in T2DM patients with hypertension and factors influencing will be reported in the study. (Rashed. AN et al, 2012 and) To date, polypharmacy ( $\geq 5$ concurrent medications), age status ( $\geq 65$ years old), multiple medical conditions and renal impairment have been shown to be the most causing influencing factors. 
Drug-related problems affect the outcomes on morbidity, mortality and cost which constitute a major public health problem. Most people with diabetes live in low- and middle-income countries like India, and these countries will also see the greatest increase over the next 19 years. The recently published ICMR-INDIAB national study reported that there are 62.4 million people with T2DM and 77 million people with pre-diabetes in India. These numbers are projected to increase to 101 million by the year 2030. (Whiting DR et al, 2011 and and Anjana RM, et al, 2011) The prevalence of diabetic retinopathy was $17.6 \%$, microalbuminuria in $26.9 \%$ neuropathy was $26.1 \%$, coronary artery disease (CAD) was $21.4 \%$ and peripheral vascular disease was $6.3 \%$. (V. Mohan et al, 2013).

\section{Objective}

The objective of this study is to assess causes and factors of DRPs in T2DM patients with any comorbid conditions so as to enhance therapeutic outcome by implementing effective medication review and psychological aspects in the treatment plan.

\section{Methods}

\section{Study Design}

The study was designed as a prospective randomized controlled intervention involving 723 participants with a followup of one year. The intervention was performed by trained community pharmacists with the help of researchers. The Independent Human Ethics Committee in Ahmedabad (Approval No.: IRB00005741), India has approved the present study design, protocols, information letters and informed consent form.

\section{Study Setup}

The trial was conducted in 2 community pharmacies at Kanpur, Uttar Pradesh, India [Anna Hajare Medical Clinic and Anjali Hospital \& Nursing Home, Kanpur.]. The present study was performed by 8 trained pharmacists in association with diabetologist. The patients were counseled in the both pharmacies randomly by the trained community pharmacists.

\section{Study Population}

723 participants were enrolled into the study those regularly visit in the both pharmacies. Participants were between 20 and 75 years of age, the prescriptions which contain antidiabetic agent(s) prescribed from the TNSTG were only considered as eligible to participate in the study. The researcher was identified the prescription and obtained written informed consent from participants before study starts.

\section{Inclusion criteria}

1. Patients with diagnosis of T2DM for $>1$ year prior to entry in the study willing and able to complete the questionnaire and on pharmacotherapy

2. Patients who are currently treated with a single or combination of injectable/oral antidiabetic drugs with or without insulin therapy

3. Treatment type must be unchanged in the previous 3 months. However, dose modifications are allowed

4. Patients who agree to participate in the study and give their written informed consent

5. Patients aged between above 20 and below 75 years old.

\section{Exclusion criteria}

1. Patients with type 1 diabetes.

2. Patients with diabetic ketoacidosis and/or hyperosmolar hyperglycaemic state.

3. Patientswithsecondarydiabetes, includingdisease of the exocrine pancreas, endocrinopathies.

4. Patients with concurrent treatment involving systemic glucocorticoids. However, inhaled, locally injected and topical use of glucocorticoids is allowed.

5. Patients suffering from severe cardiac, hepatic, renal diseases as judged by the investigator.

6. Any condition of the patient which may have an impact on objective and outcome of the trial example: patients currently undergoing major/ minor surgical

\section{Data collection}

Demographic characteristics such as age, gender, education level, income, height, weight, and body mass index were recorded. Clinical characteristics such as duration of hospital stay, duration of T2DM, presence and duration of comorbidities and presence of diabetic complications. Laboratory results and concurrent medications were also collected.

\section{Study procedures \\ Medication review}

In the intervention group medications of patients were reviewed by the trained community pharmacists by utilizing their prescription and the patient's medication evaluation profile. When prescribed by a medical specialist, details about the indication for the drug will 
be obtained from BNF (British National Formulary, 2010) and TNSTG (Standard Treatment Guidelines, 2010),. Participants were motivated to adhere for their therapy regimen though motivational interviews.

The authors identified and classified the DRPs by using PCNE. (PCNE Classification scheme for Drug related problems V5.01); PCNE is a recognized, which has been reviewed for several times and tested for its validity and reproducibility. In the present study, PCNE was classified for DRPs as 6 domains and utilized in identifying the probable reasons from the patient's prescription with the help of STGs and literatures also. The DRPs was assessed for the appropriateness of - drug indications, drug and dosage, probable drug interactions, ADR and contraindications with three references. Causes for DRP was assessed and intervened. Recommendation was communicated to the physician and changes made. The incidences of DRPs were discussed with the diabetologist and appropriate new therapy was initiated for those having DRPs. The interview on medication review was conducted for 10 -15 minutes for each patient to identify the complexity of the medication regimen and problems detected. The control group was given usual treatment.

\section{Psychological Aspect treatment}

The intervention group was provided with psychological aspect treatment (PAT) at baseline and 3, 6, 9 and 12 months by trained pharmacists, with a structured interview and motivational interviewing skills at both the study sites. The first session was conducted within one week of selection of participants for the study. The patient was informed on the contraindications, indications, side effects, administration and frequency of the medicine(s). Patients were counseled in-line with the motivational interviewing strategies to improve their medication adherence. OTC medicines were also taken into the consideration for medication review during the study period. For the PAT 25 to 30 minutes were conducted for each patient during every two visits. For the control group no PAT test was performed. (Frank Petrak et al, 2005)

\section{Workshop for Community Pharmacists}

Four sessions were conducted for the community pharmacists who were participated in this study on the above parameters. They were explained about the background of medication review, DRP score forms and evaluation pattern during the sessions. The pilot study was conducted to minimize the variability while assessing DRP score and reviewing the medication among the trained pharmacists. The assessed review on medication by trained pharmacist was reassessed by a specialist in medication review. The trained pharmacist was expected to identify more DRPs in interventional than control group pharmacists who was not attended the workshop on medication review. The assessment was carried out similar to that of pilot study. During one day workshop all the pharmacists were explained on motivational interviewing and decision making as well as communication skills.

\section{Outcome Measures}

\section{Primary outcome measures}

At the end of the study period researcher and coauthors calculated the incidences of DRP and compared the primary outcome with baseline, control and intervention groups by using a checklist which includes common drug problems. Among the enrolled patients DRPs were assessed and documented by conducting the structured interview and medication review was carried out the study participants (pharmacists).

\section{Medication Adherence with Therapy}

The 8-item self-report Morisky Medication Adherence Scale (MMAS) was used to assess medication adherence. (Morisky. DE et al, 1986)

\section{Secondary outcome measures}

Secondary outcomes include fasting plasma glucose level, hypoglycaemic episodes, morbidity, adverse effects and total incidence of patient visit to diabetiologist for consultation of probable drug related problem during the study period was measured. The incidence of clinic visit was obtained from the prescriptions.

ADR causality assessment was carried out by using Naranjo's scale and assessed by the coauthors. (Naranjo. CA, et al, 1981) All participants completed 4 validated questionnaires during the study period. The first questionnaire was given to the participants 7 days initial to the first counselling. The second questionnaire was given at 6 months; the third questionnaire was given at 9 months and the fourth was given at 12 months.

\section{Sample size}

The incidence of DPRs was weighed with respect to primary outcome of the medication review and patient counseling. From the literature review, 25\% of control group patients were encountered with DRPs and $30 \%$ of DRPs were decreased due to intervention. In a type 1 error of 0.05 , a power of $90 \%$, and a ratio 
of one between both groups of patients, multilevel randomisation resulting in a loss of power of $10 \%$, a total of 800 patients was needed to show a statistically significant difference.

\section{Statistical Analysis}

Descriptive analysis was done for the demographic characteristics of patients and other control variables both groups. Difference was tested using chi-square or t-tests. To test the effect of the intervention a multilevel design was used. Medication event was clustered within patients, and patients are clustered within pharmacies. The primary outcome, the adherence, is the dependent variable. To assess the impact of the intervention, multilevel linear and logistic regression analysis was conducted to study differences in outcome measures among patients of the intervention and control groups.
All independent variables of importance, for example socio-demographic factors and medication regimen, are included in the model to adjust for these variables. Data are analysed with SigmaStat for Windows (Demo Version) and differences in changes among the group were measured with $95 \%$ confidence intervals.

\section{Results}

Over 12 month study, participants' average $\mathrm{HBA}_{1 \mathrm{C}}$ reduced from $8.9 \%$ at initial visit to $7.5 \%$, average $\mathrm{LDL}$ was reduced from $124.1 \mathrm{mg} / \mathrm{dL}$ to $109.6 \mathrm{mg} / \mathrm{dL}$, and average BP was reduced from $141.5 \mathrm{~mm} \mathrm{Hg}$ to 132.7 $\mathrm{mm} \mathrm{Hg}$. During this time, the eye examination rate was raised from $31 \%$ to $48 \%$, and the foot examination rate was raised from $35 \%$ to $50 \%$. Only $48.25 \%$ of participants were satisfied diabetes care was better from $45.5 \%$ of participants in the highest range at baseline to $51.30 \%$ at this level after 12 months (Table No.1).

Table No. 1: Demographic and clinical characteristic of the patients $(N=723)$

\begin{tabular}{|c|c|}
\hline Characteristics & No. of patients $(\%)$ \\
\hline \multicolumn{2}{|l|}{ Gender } \\
\hline Male & $389(50.80)$ \\
\hline Female & $334(49.20)^{\prime}$ \\
\hline \multicolumn{2}{|l|}{ Age } \\
\hline Non-elderly & $427(59.10)$ \\
\hline Elderly & $296(40.90)$ \\
\hline \multicolumn{2}{|l|}{ Duration of hospital stay } \\
\hline Not more than 7 days & $515(71.23)$ \\
\hline 8 to 14 days & $157(21.72)$ \\
\hline More than 15 days & $051(07.05)$ \\
\hline \multicolumn{2}{|l|}{ Duration of type 2 diabetes mellitus } \\
\hline Not more than 10 years & $247(34.16)$ \\
\hline 11 to 20 years & $224(30.98)$ \\
\hline 21 to 30 years & $108(14.94)$ \\
\hline Unknown duration & $070(09.68)$ \\
\hline \multicolumn{2}{|l|}{ Duration of hypertension } \\
\hline Not more than 10 years & $209(28.91)$ \\
\hline 11 to 20 years & $178(24.62)$ \\
\hline 21 to 30 years & $162(22.41)$ \\
\hline Unknown duration & $174(24.01)$ \\
\hline \multicolumn{2}{|l|}{$\mathrm{HbA1 \textrm {c }}$} \\
\hline Achieved target $(<6.5)$ & $210(24.04)$ \\
\hline Did not achieve target $(\geq 6.5)$ & $513(45.96)$ \\
\hline \multicolumn{2}{|l|}{ Diabetic complications $\dagger$} \\
\hline Diabetic retinopathy & $84(11.62)$ \\
\hline Diabetic foot ulcer & $118(16.32)$ \\
\hline Diabetic neuropathy & $073(10.10)$ \\
\hline \multicolumn{2}{|l|}{ Comorbiditiesł } \\
\hline Renal impairment & $94(13.00)$ \\
\hline Cardiovascular disease & $123(17.01)$ \\
\hline Dyslipidemia & $104(14.38)$ \\
\hline Stroke & $051(07.05)$ \\
\hline Gastrointestinal disease & $012(1.66)$ \\
\hline Liver impairment and Bronchial asthma & $021(2.09)$ \\
\hline
\end{tabular}


In the present study, the DRPs in TDM and comorbid patients observed are recorded in Table No. 2. The type of problems experienced was typically due to errors in the medication adherence and compliance. Out of the 723 patients $6.92 \%(n=50)$ of the patients experienced adverse drug reactions that were non allergic in nature, $26.96 \%(n=193)$ of them showed problems associated with choice of the drug, $16.45 \%$ of the patients developed dosing related problems, 14.94\% $(n=108)$ of the patients experienced drug use problems as they did not administer the drugs at all, $13.28 \%(n=96)$ of them showed potential drug interactions. $31.53 \%$ of the reported other problems like patient dissatisfied with therapy despite taking drug(s) correctly $(3.32 \%)$ and insufficient awareness of health and diseases (26.28\%) and $1.94 \%$ experienced therapy failure.

Table No. 2: Drug related problems in T2DM patients with hypertension $(n=723)$

\begin{tabular}{|c|c|c|}
\hline Code & Problems* & $\begin{array}{l}\text { No. of problem } \\
(\%)\end{array}$ \\
\hline P1 & Adverse reactions & $45(6.22)$ \\
\hline P1.1 & Side effects suffered (non-allergic) & $50(6.92)$ \\
\hline P2 & Drug choice problems & $167(23.10)$ \\
\hline P2.1 & $\begin{array}{l}\text { Inappropriate drug (not most appropriate for } \\
\text { indication) }\end{array}$ & $64(8.85)$ \\
\hline P2.2 & $\begin{array}{l}\text { Inappropriate drug form (not most appropriate for } \\
\text { indication) }\end{array}$ & $11(1.52)$ \\
\hline P2.3 & $\begin{array}{l}\text { Inappropriate duplication of therapeutic group or } \\
\text { active ingredient }\end{array}$ & $18(2.49)$ \\
\hline P2.4 & Contraindication for drug & $59(8.16)$ \\
\hline P2.5 & No clear indication for drug use & $9(1.24)$ \\
\hline P2.6 & No drug but clear indication & $32(4.43)$ \\
\hline P3 & Dosing problems & $123(17.01)$ \\
\hline P3.1 & $\begin{array}{l}\text { Drug dose too low or dosage regime not frequent } \\
\text { enough }\end{array}$ & $8(1.11)$ \\
\hline P3.2 & Drug dose too high or dosage regime too frequent & $88(12.17)$ \\
\hline P3.3 & Duration of treatment too short & $10(1.38)$ \\
\hline P3.4 & Duration of treatment too long & $13(1.80)$ \\
\hline P4 & Drug use problems & $99(13.69)$ \\
\hline P4.1 & Drug not taken/administered at all & $108(14.94)$ \\
\hline P5 & Interactions & $133(18.40)$ \\
\hline P5.1 & Potential interaction & $96(13.28)$ \\
\hline P6 & Others & $202(27.94)$ \\
\hline P6.1 & $\begin{array}{l}\text { Patient dissatisfied with therapy despite taking drug(s) } \\
\text { correctly }\end{array}$ & $24(3.32)$ \\
\hline P6.2 & $\begin{array}{l}\text { Insufficient awareness of health and diseases } \\
\text { (possibly leading to future problems) }\end{array}$ & $190(26.28)$ \\
\hline P6.4 & Therapy failure (reason unknown) & $14(1.94)$ \\
\hline
\end{tabular}

* Only problems that have a frequency of more than one were included.

The causes of the above mentioned DRPs in T2DMwith hypertension were evident in 696 patients as shown in Table No. 3. The major causes assessed were due to drug and dose selection $47.55 \%(\mathrm{n}=331)$, drug use process such as in appropriate timing of administration, drug under administered and patient unable to use the drug or dosage form as directed. The second major cause of the DRPs in these patients were patient/ psychological associated evident in 39.65\% $(\mathrm{n}=276)$ of the patients, followed by drug use process in $14.65 \%(n=102)$. In $8.47 \%(n=59)$ it was due to lack of proper instructions for use of drugs, unawareness of the reason for drug treatment and unable to understand the local language. $6.6 \%(\mathrm{n}=46)$ due to logistic issues such as prescribed drug not available (anymore) and prescribing errors. 
Table No. 3: Causes of DRPs in T2DM patients with hypertension $(n=696)$

\begin{tabular}{|l|l|l|}
\hline \multicolumn{1}{|c|}{ Code } & \multicolumn{1}{|c|}{ Causes* } & \multicolumn{1}{|c|}{ No. of problem (\%) } \\
\hline C1 & Drug/ Dose selection & $\mathbf{3 4 8 ( 5 0 . 0 )}$ \\
\hline C1.1 & Inappropriate drug selection & $140(20.12)$ \\
\hline C1.2 & Inappropriate dosage selection & $118(16.95)$ \\
\hline C1.5 & Synergistic/preventive drug required and not given & $35(5.03)$ \\
\hline C1.8 & Manifest side effect, no other cause & $38(5.46)$ \\
\hline C2 & Drug use process & $\mathbf{9 3 ( 1 3 . 6 2 )}$ \\
\hline C2.1 & $\begin{array}{l}\text { Inappropriate timing of administration and/or dosing } \\
\text { intervals }\end{array}$ & $18(2.59)$ \\
\hline C2.2 & Drug underused/under-administered & $73(10.49)$ \\
\hline C2.6 & Patient unable to use drug/form as directed & $11(1.58)$ \\
\hline C3 & Information & $\mathbf{5 1}(7.33)$ \\
\hline C3.1 & Instructions for use/taking not known & $21(3.02)$ \\
\hline C3.2 & Patient unaware of reason for drug treatment & $19(2.73)$ \\
\hline C3.4 & Patient unable to understand local language & $19(2.73)$ \\
\hline C4 & Patient/Psychological & $\mathbf{2 4 2 ( 3 4 . 7 7 )}$ \\
\hline C4.1 & Patient forgets to use/take drug & $31(4.54)$ \\
\hline C4.2 & Patient has concerns with drugs & $14(2.01)$ \\
\hline C4.3 & Patient suspects side-effect & $21(3.02)$ \\
\hline C4.5 & Patient unwilling to bother physician & $13(1.88)$ \\
\hline C4.7 & Patient unwilling to adapt life-style & $68(9.77)$ \\
\hline C4.8 & Burden of therapy & $94(13.50)$ \\
\hline C4.9 & Treatment not in line with health beliefs & $35(5.03)$ \\
\hline C5 & Logistic & $\mathbf{1 4}(\mathbf{2 . 0 1 )}$ \\
\hline C5.1 & Prescribed drug not available (anymore) & $33(4.74)$ \\
\hline C5.2 & Prescribing error (only in case of slip of the pen) & $13(1.87)$ \\
\hline & $*$ Only causes that have frequency of more than one were included. \\
\hline
\end{tabular}

From Table No. 4, the factors causing the DRPs in T2DM patients with hypertension are the age of the patient, intake of number of medicines, duration of hospital stay and other comorbid conditions like microvascular complications, cardiovascular events, renal as well as liver impairment and hyperlipidaemia. In the present study, we have compared the factors and occurrence of DRPs like adverse drug reaction, drug choice problems, dosing problems Adverse drug reactions: As summarized in table no: 4, among the 375 patients; 51 of them had experienced ADRs whereas 324 of them did not. Among the group of patients who had experienced them, about $45.1 \%$ of them were elderly patients and $55.90 \%$ of them were non elderly patients. On the other hand, among the 324 who were not affected by any ADRs, $41.36 \%$ and $58.64 \%$ were elderly and non elderly respectively. Depending upon the second factor i.e., polypharmacy, $89.39 \%$ of them were taking many medicines for different conditions experienced ADRs while the rest $19.61 \%$ were not taking polypharmacy. Whereas out of those 324 who did not have any ADRs, among them $76.6 \%$ were taking polypharmacy while $23.4 \%$ of the patients were not. Considering the duration of hospital stay as one of the factor for occurrence of ADRs, $60.78 \%$ of the patients had them in the duration of $\leq 1$ week, while $39.22 \%$ of them for the duration of $>1$ week. In contrast with this, the ones who had not experienced ADRs, for duration of $\leq 1$ week and $>1$ week were $62.96 \%$ and $37.04 \%$ respectively. The patients living with other complications like microvascular complications, cardiovascular events, renal impairment, liver impairment and hyperlipidaemia and experienced ADRs were $58.82 \%, 40.06 \%, 54.90 \%, 7.84 \%$ and $41.18 \%$ respectively and the ones without these above mentioned complications but yet ADR occurrence was reported were $41.18 \%, 52.94 \%, 45.10 \%, 92.16 \%$ and $58.82 \%$ respectively. Among the 324 who had no ADRs but living with the above mentioned complications were $54.63 \%, 55.86 \%, 58.02 \%, 8.02 \%$ and $29.32 \%$ respectively, while the patients without the ADRs and also without the above complications were $45.37 \%$, $44.14 \%, 41.98 \%, 91.98 \%$ and $70.68 \%$ respectively. 
Table No. 4: Comparison between factors and occurrence of adverse reactions, drug choice problems, and dosing problems (375)

\begin{tabular}{|c|c|c|c|c|c|c|c|c|c|}
\hline \multirow[t]{2}{*}{ Factors } & \multicolumn{3}{|c|}{$\begin{array}{c}\text { Adverse reactions }(n=375) \\
n(\%)\end{array}$} & \multicolumn{3}{|c|}{$\begin{array}{l}\text { Drug choice problem }(\mathrm{n}=375) \mathrm{n} \\
(\%)\end{array}$} & \multicolumn{3}{|c|}{ Dosing problem $(n=375) n$} \\
\hline & $\begin{array}{c}\text { Yes }(\mathrm{n}= \\
51)\end{array}$ & $\begin{array}{c}\text { No(n }= \\
324)\end{array}$ & P-value & $\begin{array}{l}\text { Yes }(n= \\
149)\end{array}$ & $\begin{array}{c}\text { No }(\mathrm{n}= \\
226)\end{array}$ & P-value & $\begin{array}{c}\text { Yes }(\mathrm{n}= \\
118)\end{array}$ & $\begin{array}{c}\text { No }(\mathrm{n}= \\
257)\end{array}$ & P-value \\
\hline \multicolumn{10}{|l|}{ Elderly } \\
\hline Yes & $23(45.10)$ & $\begin{array}{l}134 \\
(41.36)\end{array}$ & \multirow[t]{2}{*}{$>0.9 \mathrm{a}$} & $62(41.61)$ & $\begin{array}{l}161 \\
(71.24)\end{array}$ & \multirow[t]{2}{*}{$<0.01 \mathrm{a}^{*}$} & $73(61.86)$ & $\begin{array}{l}148 \\
(57.59)\end{array}$ & \multirow[t]{2}{*}{$0.5 \mathrm{a}$} \\
\hline No & $28(55.90)$ & $\begin{array}{l}190 \\
(58.64)\end{array}$ & & $87(58.39)$ & $65(28.76)$ & & $45(38.14)$ & $\begin{array}{l}109 \\
(42.41)\end{array}$ & \\
\hline \multicolumn{10}{|c|}{ Polypharmacy } \\
\hline Yes & $41(89.39)$ & $134(76.6)$ & $>0.9 \mathrm{a}$ & $120(80.54)$ & $\begin{array}{l}173 \\
(76.45)\end{array}$ & \multirow[t]{2}{*}{$0.05 \mathrm{a}$} & $81(68.64)$ & $\begin{array}{l}201 \\
(78.21)\end{array}$ & \multirow[t]{2}{*}{$0.1 \mathrm{a}$} \\
\hline No & $10(19.61)$ & $41(23.4)$ & & $29(19.46)$ & $53(23.45)$ & & $37(31.36)$ & $56(21.79)$ & \\
\hline \multicolumn{10}{|c|}{ Duration of hospital stay } \\
\hline $\begin{array}{l}\leq 1 \\
\text { week }\end{array}$ & $31(60.78)$ & $\begin{array}{l}204 \\
(62.96)\end{array}$ & \multirow[t]{2}{*}{$0.5 \mathrm{a}$} & $95(63.74)$ & $\begin{array}{l}188 \\
(83.19)\end{array}$ & \multirow[t]{2}{*}{$0.05 a^{*}$} & $90(76.7)$ & $\begin{array}{l}193 \\
(75.08)\end{array}$ & \multirow[t]{2}{*}{$0.9 \mathrm{a}$} \\
\hline $\begin{array}{l}>1 \\
\text { week }\end{array}$ & $20(39.22)$ & $\begin{array}{l}120 \\
(37.04)\end{array}$ & & $54(36.26)$ & $38(16.81)$ & & $28(23.73)$ & $64(24.92)$ & \\
\hline \multicolumn{10}{|c|}{ Microvascular complication } \\
\hline Yes & $30(58.82)$ & $\begin{array}{l}177 \\
(54.63)\end{array}$ & \multirow[t]{2}{*}{$0.5 \mathrm{a}$} & $105(70.47)$ & $\begin{array}{l}131 \\
(57.96)\end{array}$ & \multirow[t]{2}{*}{$0.01 \mathrm{a}$} & $\begin{array}{l}100 \\
(84.74)\end{array}$ & $154(5992)$ & \multirow[t]{2}{*}{$0.1 \mathrm{a}$} \\
\hline No & $21(41.18)$ & $\begin{array}{l}147 \\
(45.37)\end{array}$ & & $44(29.53)$ & $95(42.04)$ & & $18(15.25)$ & $\begin{array}{l}103 \\
(40.08)\end{array}$ & \\
\hline \multicolumn{10}{|c|}{ Cardiovascular events } \\
\hline Yes & $24(40.06)$ & $\begin{array}{l}181 \\
(55.86)\end{array}$ & \multirow[t]{2}{*}{$0.1 \mathrm{~b}$} & $97(65.10)$ & $\begin{array}{l}138 \\
(61.06)\end{array}$ & \multirow[t]{2}{*}{$0.05 \mathrm{a}$} & $77(65.24)$ & $\begin{array}{l}158 \\
(61.48)\end{array}$ & \multirow[t]{2}{*}{$0.5 \mathrm{a}$} \\
\hline No & $27(52.94)$ & $\begin{array}{l}143 \\
(44.14)\end{array}$ & & $52(34.90)$ & $88(38.93)$ & & $41(34.74)$ & $99(38.52)$ & \\
\hline \multicolumn{10}{|c|}{ Renal impairment } \\
\hline Yes & $28(54.90)$ & $\begin{array}{l}188 \\
(58.02)\end{array}$ & \multirow[t]{2}{*}{$>0.9 \mathrm{a}$} & $94(63.09)$ & $85(37.61)$ & \multirow[t]{2}{*}{$0.05 a^{*}$} & $80(67.80)$ & $\begin{array}{l}126 \\
(40.03)\end{array}$ & $0.05 a^{*}$ \\
\hline No & $23(45.10)$ & $\begin{array}{l}136 \\
(41.98)\end{array}$ & & $55(36.91)$ & $\begin{array}{l}141 \\
(62.39)\end{array}$ & & $38(32.20)$ & $\begin{array}{l}131 \\
(50.97)\end{array}$ & \\
\hline \multicolumn{10}{|c|}{ Liver impairment } \\
\hline Yes & $4(7.84)$ & $26(8.02)$ & \multirow[t]{2}{*}{$>0.9 \mathrm{~b}$} & $16(10.74)$ & $21(9.29)$ & \multirow[t]{2}{*}{$0.50 \mathrm{a}$} & $18(15.25)$ & $16(6.22)$ & \multirow[t]{2}{*}{$0.50 \mathrm{a}$} \\
\hline No & $47(92.16)$ & $\begin{array}{l}298 \\
(91.98)\end{array}$ & & $133(89.26)$ & $\begin{array}{l}205 \\
(90.71)\end{array}$ & & $\begin{array}{l}100 \\
(84.74)\end{array}$ & $\begin{array}{l}241 \\
(93.77)\end{array}$ & \\
\hline \multicolumn{10}{|c|}{ Hyperlipidemia } \\
\hline Yes & $21(41.18)$ & $95(29.32)$ & $0.5 \mathrm{a}$ & $41(27.52)$ & $88(38.94)$ & $0.05 a^{*}$ & $35(29.66)$ & $93(36.19)$ & $0.50 \mathrm{a}$ \\
\hline No & $30(58.82)$ & $\begin{array}{l}229 \\
(70.68)\end{array}$ & & $108(72.48)$ & $\begin{array}{l}138 \\
(61.06)\end{array}$ & & $83(70.34)$ & $\begin{array}{l}164 \\
(63.81)\end{array}$ & \\
\hline
\end{tabular}

a Computed using Continuity Correction; b Computed using Fisher's Exact Test;

* Statistically significant $(\mathrm{p}<0.05)$.

Drug Choice Problems: Among the total 375 patients, 149 of them experienced DCPs while 226 did not show any kind of DCPs. Among the 149 of the patients in whom DCPs occurred, $41.61 \%$ were elderly and the rest were non elderly, $58.39 \%$. $80.54 \%$ of them were taking polypharmacy while $19.46 \%$ were not. It was evident in the patients whose duration of stay in the hospital was for $\leq 1$ week and $>1$ week by $63.74 \%$ and $36.26 \%$ respectively. The occurrence of DCPs in patients with microvascular complications, cardiovascular events, 
renal impairment, liver impairment and hyperlipidaemia were $70.47 \%, 65.10 \%, 63.09 \%, 10.74 \%$ and $27.52 \%$ respectively, whereas in the patients without the above complications but still the DCPs were evident were $29.53 \%, 34.90 \%, 36.91 \%, 89.26 \%$ and $72.48 \%$ respectively. On the other hand, among the 226 patients who did not experience DCPs, $71.24 \%$ were elderly and $28.76 \%$ were non elderly patients. $76.45 \%$ were taking polypharmacy while $23.45 \%$ were not. About $83.19 \%$ of the patients who were hospitalized for $</=1$ week and $16.81 \%$ for $>1$ week had not experienced any kind of DCPs. The patients living with the other complications like microvascular problems, cardiovascular events, renal and liver impairment and hyperlipidaemia but no DCPs were evident were 57.96\%, 61.06\%, 37.61\%, $9.29 \%, 38.94 \%$ respectively and the rest of them had no complications and no DCPs.

Dosing problems: Among the sample size of 375, 118 of them experienced dosing problems (DPs) whereas 257 of them did not. Among the ones who experienced DPs ( $\mathrm{n}=118), 61.86 \%$ are elderly patients and remaining $38.14 \%$ of them are non-elderly patients. About $68.64 \%$ of them take Polypharmacy and the rest $31.36 \%$ of them do not. $76.7 \%$ of the patients reported DPs within $\leq 1$ week of hospital stay while $23.73 \%$ of the patients within $>1$ week of hospital stay. The patients in whom the DPs were evident and who were living with other complications like microvascular, cardiovascular events, renal impairment, liver impairment and hyperlipidaemia were $84.74 \%, 65.24 \%, 67.80 \%, 15.25 \%$ and $29.66 \%$ respectively, whereas the remaining experienced DPs but did not have any of the mentioned complications. Among the ones, in whom DPs were not seen $(\mathrm{n}=257), 57.59 \%$ were elderly patients while the rest 42.41\% were non elderly patients. $78.21 \%$ were taking Polypharmacy but $21.79 \%$ were not. In $\leq 1$ week or $>1$ week of hospitalization, $75.08 \%$ and $24.92 \%$ respectively, the patients did not experience any DPs. With microvascular, cardiovascular, renal, liver and hyperlipidaemia complications of $59.92 \%, 61.48 \%$, $40.03 \%, 6.22 \%$ and $36.19 \%$ respectively, the patients did not experience DPs whereas the rest of them had no complications and also no DPs.

Drug Use Problems: Among the 374 sample size, the patients who experienced DUPs were 97 and who did not have DUPs were 227. In both the scenarios, the majority of the patients affected were the non-elderly patients, $68.04 \%$ and $57.72 \%$ respectively but among the elderly patients, $31.96 \%$ and $42.28 \%$ respectively. The patients who are experiencing DUPs while taking poly pharmacy are $68.0 \%$, while not taking polypharmacy are $32.0 \%$ whereas, the ones not have DUPs while taking and not taking polypharmacy are $70.67 \%$ and $29.33 \%$. The DUPs were high in the patients whose duration of stay in hospital is $\leq 1$ week, $75.26 \%$ compared to the ones with hospitalization for $>1$ week, $24.74 \%$. The patients with the complications like the microvascular, cardiovascular, renal impairment, liver impairment and hyperlipidaemia, in whom the DUPs were evident were $64.95 \%, 53.61 \%, 49.48 \%, 10.31 \%$ and $40.21 \%$ respectively.

Drug interactions: The patients who experienced drug interactions were 125 and who did not were 199. In this type of DRP, the majority of patients affected were from the elderly group of patients i.e., $61.60 \%$ and $58.02 \%$ respectively. The patients in whom, the drug interactions were evident while taking and not taking polypharmacy are $94.4 \%$ and $69.75 \%$ respectively. About $75.20 \%$ of them showed drug interactions in $\leq 1$ week of duration of stay in hospital and $24.80 \%$ within $>1$ week of hospital stay. The drug interaction were reported in patients living with microvascular, cardiovascular, renal, liver and hyperlipidaemia complications by $67.20 \%$, $82.40 \%, 58.40 \%, 1.60 \%$ and $62.60 \%$ respectively.

Other Problems: Overall 187 of the patients had experienced other DRPs while 137 of the patients did not. Among them the percentile of elderly patients is $61.50 \%$ and $56.93 \%$ and that of non-elderly is $38.50 \%$ and $43.06 \%$ respectively. In the patients who were taking polypharmacy, the evidence of other DRPs were high 78.61\% when compared to those who were not taking polypharmacy, $21.39 \% .72 .19 \%$ of them showed other problems in duration of $\leq 1$ week of hospital stay and $27.81 \%$ in duration of $>1$ week hospitalization. The other DRPs in patients with microvascular, cardiovascular, renal, liver and hyperlipidaemia complications are evident with the percentile of $72.73 \%$, $65.78 \%, 52.94 \%, 6.42 \%$ and $69.89 \%$ respectively. 
Table No. 5: Comparison between factors and occurrence of drug use problems, drug interactions, and other problems (375)

\begin{tabular}{|c|c|c|c|c|c|c|c|c|c|}
\hline \multirow[t]{2}{*}{ Factors } & \multicolumn{3}{|c|}{ Drug use problems } & \multicolumn{3}{|c|}{ Drug interactions } & \multicolumn{3}{|c|}{ Other problems } \\
\hline & $\begin{array}{c}\text { Yes }(n= \\
97)\end{array}$ & $\begin{array}{c}\text { No }(n= \\
227)\end{array}$ & p-value & $\begin{array}{c}\text { Yes }(n= \\
125)\end{array}$ & $\begin{array}{c}\text { No }(n= \\
324\end{array}$ & p-value & $\begin{array}{c}\text { Yes }(n= \\
187)\end{array}$ & $\begin{array}{c}\text { No }(n= \\
137)\end{array}$ & p-value \\
\hline \multicolumn{10}{|l|}{ Elderly } \\
\hline Yes & $31(31.96)$ & $96(42.28)$ & \multirow[t]{2}{*}{$0.2 \mathrm{a}$} & $77(61.60)$ & 188 & \multirow[t]{2}{*}{$0.9 \mathrm{a}$} & $115(61.50)$ & $78(56.93)$ & \multirow[t]{2}{*}{$0.8 \mathrm{a}$} \\
\hline No & $66(68.04)$ & $\begin{array}{l}131 \\
(57.72)\end{array}$ & & $48(38.40)$ & $\begin{array}{l}(58,02) \\
136 \\
(41.98)\end{array}$ & & $72(38.50)$ & $59(43.06)$ & \\
\hline \multicolumn{10}{|c|}{ Polypharmacy } \\
\hline Yes & $69(68.0)$ & 160 & \multirow[t]{2}{*}{$0.2 \mathrm{a}$} & $118(94.40)$ & 226 & \multirow[t]{2}{*}{$0.001 \mathrm{a}^{*}$} & $147(78.61)$ & 109 & \multirow[t]{2}{*}{$>0.9 \mathrm{a}$} \\
\hline No & $28(32.0)$ & $\frac{(70.67)}{67(29.33)}$ & & 7 (5.6) & $\frac{(69.75)}{98(30.25)}$ & & $40(21.39)$ & $\frac{(79.56)}{28(20.44)}$ & \\
\hline \multicolumn{10}{|c|}{ Duration of hospital stay } \\
\hline $\begin{array}{l}\leq 1 \\
\text { week }\end{array}$ & $73(75.26)$ & $\begin{array}{l}154 \\
(67.90)\end{array}$ & \multirow[t]{2}{*}{$0.8 \mathrm{a}$} & $94(75.20)$ & $\begin{array}{l}233 \\
(71.91)\end{array}$ & \multirow[t]{2}{*}{$0.8 \mathrm{a}$} & $135(72.19)$ & $\begin{array}{l}103 \\
(75.18)\end{array}$ & \multirow[t]{2}{*}{$0.2 \mathrm{a}$} \\
\hline $\begin{array}{l}>1 \\
\text { week }\end{array}$ & $24(24.74)$ & $73(32.10)$ & & $31(24.80)$ & $91(28.09)$ & & $52(27.81)$ & $34(24.82)$ & \\
\hline \multicolumn{10}{|c|}{ Microvascular complications } \\
\hline Yes & $63(64.95)$ & $\begin{array}{l}118 \\
(60.49)\end{array}$ & \multirow[t]{2}{*}{$>0.9 \mathrm{a}$} & $84(67.20)$ & $\begin{array}{l}208 \\
(64.20)\end{array}$ & \multirow[t]{2}{*}{$0.6 \mathrm{a}$} & $136(72.73)$ & $79(57.66)$ & \multirow[t]{2}{*}{$0.2 \mathrm{a}$} \\
\hline No & $34(35.05)$ & $\begin{array}{l}109 \\
(39.51)\end{array}$ & & $41(32.80)$ & $\begin{array}{l}116 \\
(35.80)\end{array}$ & & $51(27.27)$ & $58(42.34)$ & \\
\hline \multicolumn{10}{|c|}{ Cardiovascular disease } \\
\hline Yes & $52(53.61)$ & $\begin{array}{l}132 \\
(58.33)\end{array}$ & \multirow[t]{2}{*}{$0.4 \mathrm{a}$} & $103(82.40)$ & $\begin{array}{l}136 \\
(41.98)\end{array}$ & \multirow[t]{2}{*}{$\begin{array}{l}< \\
0.001 \mathrm{a}^{*}\end{array}$} & $123(65.78)$ & $75(54.74)$ & \multirow[t]{2}{*}{$0.3 \mathrm{a}$} \\
\hline No & $45(46.39)$ & $95(41.67)$ & & $22(17.60)$ & $\begin{array}{l}188 \\
(58.02)\end{array}$ & & $64(34.22)$ & $62(45.26)$ & \\
\hline \multicolumn{10}{|c|}{ Renal impairment } \\
\hline Yes & $48(49.48)$ & $97(39.51)$ & \multirow[t]{2}{*}{$0.4 \mathrm{a}$} & $73(58.40)$ & $\begin{array}{l}151 \\
(46.40)\end{array}$ & \multirow[t]{2}{*}{$0.8 \mathrm{a}$} & $99(52.94)$ & $71(51.82)$ & \multirow[t]{2}{*}{$>0.9 \mathrm{a}$} \\
\hline No & $49(50.52)$ & $\begin{array}{l}130 \\
(60.49)\end{array}$ & & $52(41.60)$ & $\begin{array}{l}173 \\
(53.40)\end{array}$ & & $88(47.06)$ & $66(48.18)$ & \\
\hline \multicolumn{10}{|c|}{ Liver impairement } \\
\hline Yes & $10(10.31)$ & $12(5.25)$ & \multirow[t]{2}{*}{$0.5 b$} & $2(1.60)$ & $21(6.48)$ & \multirow[t]{2}{*}{$0.02 b^{*}$} & $12(6.42)$ & $8(5.84)$ & $>0.9 \mathrm{a}$ \\
\hline No & $87(89.69)$ & $\begin{array}{l}215 \\
(94.75)\end{array}$ & & $123(98.40)$ & $\begin{array}{l}303 \\
(93.52)\end{array}$ & & $175(93.58)$ & $\begin{array}{l}129 \\
(94.16)\end{array}$ & \\
\hline Hyperli & jidemia & & & & & & & & \\
\hline Yes & $39(40.21)$ & $81(35.80)$ & $0.2 \mathrm{a}$ & $78(62.40)$ & $\begin{array}{l}185 \\
(57.10)\end{array}$ & $0.9 \mathrm{a}$ & $112(59.89)$ & $78(56.93)$ & $0.8 \mathrm{a}$ \\
\hline No & $58(59.79)$ & $\begin{array}{l}146 \\
(64.20)\end{array}$ & & $47(37.60)$ & $\begin{array}{l}139 \\
(42.90)\end{array}$ & & $75(40.11)$ & $59(43.06)$ & \\
\hline
\end{tabular}

a Computed using Continuity Correction; b Computed using Fisher's Exact Test;

* Statistically significant $(\mathrm{p}<0.05)$.

\section{Discussion}

The population of India is over 1000 million (1260 million in 2012). According to the International Diabetes Federation, 61.3 million people in India had diabetes in 2011. That figure is projected to rise to 101.2 million by 2030 .The prevalence rate of diabetes in the urban areas of India is thought to be 9 per cent and 3 per cent approximately in the rural areas, of the total population. This statistics helps to give an idea of the scale of the problem. (Population Reference Bureau, 2012 and Global Diabetes community). The sanofi-aventis India SITE study (Screening India's Twin 
Epidemic), rolled out during 2009/ 2010, was a crosssectional epidemiological study of 16,000 patients from 800 centers in Maharashtra, New Delhi, Tamil Nadu, Andhra Pradesh, West Bengal, Karnataka, Gujarat, and Madhya Pradesh. About 60 percent of the surveyed population suffered from diabetes, hypertension, or both, and 70 percent of the patients had uncontrolled diabetes. [Sanofi-aventis' India SITE study shows 62\% of diabetic population in New Delhi has 'uncontrolled' diabetes. Mumbai, India: Aventis Pharma Limited; 2010.]

According to the citations in the Population Reference Bureau: 2012 World Population Data Sheet, the non communicable diseases (NCDs), such as cardiovascular diseases, cancers, diabetes, and chronic lung diseases, are the leading causes of death in all regions except sub-Saharan Africa. In 2008, almost two-thirds of all the deaths globally were due to NCDs. Nearly 4 out of 5 deaths from NCDs occurred in low- and middleincome countries. While the number of people suffering and dying from NCDs will continue to increase around the world over the next several decades, the greatest increases are expected in low-income countries. In South Asia, deaths due to NCDs are projected to increase from half to almost three-quarters of all deaths between 2008 and 2030. Population Reference Bureau; 2012 World Population Data Sheet. Washington DC, USA: USAID; 2012]

DRPs the most important aspect in the pharmaceutical care. The terms such as medication errors are often used to describe this concept, but it is different from the actual understanding of DRPs. The medication errors refer to the mistakes in the process that could lead to problems in an individual whereas, DRPs can occur when prescribing, dispensing or taking/ administering medicines. There are several classifications framed to understand the factors, causes and problems arising due to drugs but in this study PCNE classification for DRP is used. A DRP is an event or circumstance involving drug therapy that actually or potentially interferes with desired health outcomes. (Bob W. van Roozendaal and Ines Krass, 2009)

This study was conducted on 723 patients, out of which $389(50.8 \%)$ were male and 334 (49.2\%) were female patients. To reduce the drug related problems the causes and factors should be known. According to the PCNE classification, 6 major domains of Drug related problems in this study such as adverse drug reactions, drug choice problem, dosing problem, drug use problem, drug interactions and others were recorded.

\section{Adverse Reactions}

The WHO defines adverse drug reaction as "a response to a drug that is noxious and unintended and occurs at doses normally used in man for the prophylaxis, diagnosis or therapy of disease, or for modification of physiological function". Adverse drug reaction are classified as side effects that are allergic, non allergic or toxic. 50 patients $(6.92 \%)$ reported having experienced at least one episode of reaction of any kind. In contrast with the similar studies conducted in 2 different countries, Australia based study 43 out of 148 patients $(6.3 \%)$ and in Malaysia based study 25 out of $387(6.5 \%)$ patients experienced these type of reactions, assuming that same category of anti diabetic drugs and anti hypertensive drugs were given. This kind of drug related problems can be an outcome of prescribing error, but unexpected ADRs may also occur at normal dosages of a well selected drug.

\section{Drug Choice Problems}

Patient gets or is going to get a wrong (or no drug) drug for their disease and/ or condition. This is usually a prescribing error. These errors commonly occur due inappropriate drug selection and 140 cases were reported for the same. This category of problem was recorded 193 times. 64 out of 193 drug choice problems were due to the administration of the drugs that were inappropriate for the patient's condition and 59 of 193 were due to contraindication of the drug, followed by others. In some patients, synergistic or preventive drug was required but the patients did not receive, reported cases were 35. The Drug choice problem contributes to $26.69 \%$ of the errors. In the Australia based study, this category of DRP contributes $30.2 \%$ of all DRPs and the most precipitating factor is no drug prescribed even when the indication of illness is clear i.e., 182 of 206 (26.7\%). Whereas in Malaysia, this category of DRP contributes $22.5 \%$ of the rest DRPs, and the leading factors are inappropriate drug administration followed by contraindications of the drug.

\section{Dosing Problems}

This category of DRP occurs when the patient gets the right drug, but in insufficient amount than required. This can be a prescribing error or a drug use error. This occurs due to inappropriate dosage selection for which 118 reports were recorded. Dosing errors are recorded 
119 times in this study constituting for $16.45 \%$ of all the DRPs. 88 out of 119 of this DRP are due to high dose or dosage regime too frequent. This is the leading contributing factor for the dosing related drug problem in the studies based in Australia (27 out of 40) and Malaysia (44 out of 62). This is a very serious factor and through monitoring is required during the period of therapy. Otherwise, the dosing related drug problems constitute to $16 \%$ and $5.9 \%$ of the overall DRPs in Malaysia and Australia respectively.

\section{Drug Use Problems}

These kinds of DRPs arise when the patient administers the wrong drug or does not take any drug. This can be drug use error, administration error and/or filling error in the pharmacy. Proper patient counseling or educating the patient about the disease and the need for treatment can help overcome this problem of medication adherence and discouraging the idea of self medication and over the counter medication can be effective in significantly reducing the risk of wrong medication. Here the risk of potential non adherence was the major factor, 108 cases were recorded contributing to $14.94 \%$ of all the DRPs. The causes of DRP due to drug use $(n=102)$ were inappropriate timing of administration and dosing intervals 18 out of 102 , drug unused or under-administered were 73 of 102 and 11 out of 102 were because patients were unable to use the medication as directed.12.9\% and 3.8\% was seen for potential non adherence in Malaysia and Australia respectively.

\section{Potential Interactions}

The potential drug-drug or drug-food interaction is a form of prescribing or drug-use error.96 cases were reported in the study. The interactions identified were mostly based on established literature and evidence recorded and complied in authenticated resources. The drug interactions contribute to about $13.28 \%$ of all the DRPs, where as in Australia and Malaysia they contribute to about $15.1 \%$ and $16.3 \%$ of the rest of the DRPs respectively.

\section{Other Problems}

The other problems reported in this study were $228,31.53 \%$ of all the DRPs recorded. On further interviewing and assessing the data of those 288 cases, it was found that 190 of 228 had inadequate awareness about the health and disease, that could precipitate and cause long term effects, 24 of 228 were not satisfied with the therapy without any error of non adherence and 14 of 228 experienced failure of the therapy, however the reason couldn't be noticed. By contrast, the leading cause reported in Malaysia was inadequate awareness but in Australia it was therapy failure.

\section{Conclusion:}

The findings of the study have less significant improvement in their primary and secondary outcomes. It may be concluded, therefore, that the intervention pharmacists showed no demonstrable influence on any of the intermediate health outcomes relating to metabolic control or on therapeutic adherence in T2DM that was significantly different from that exerted by the control cohort of pharmacists.

\section{References:}

1. Carrera Boada. CA and Martínez-Moreno. JM. Pathophysiology of diabetes mellitus type 2: beyond the duo "insulin resistance-secretion deficit". Nutr Hosp, 2013; 28(Supl. 2): $78-87$.

2. Whiting DR, Guariguata L, Weil C, Shaw J. IDF Diabetes Atlas: Global estimates of the prevalence of diabetes for 2011 and 2030. Diabetes Res Clin Pract 2011; 94: 311-21.

3. Anjana RM, Pradeepa R, Deepa M, Datta M, Sudha V, Unnikrishnan R, et al. On behalf of the ICMR-INDIAB Collaborative Study Group. Prevalence of diabetes and prediabetes (impaired fasting glucose and/or impaired glucose tolerance) in urban and rural India: Phase I results of the ICMR - INDIAB study. Diabetologia, 2011; 54: 3022 - 3027.

4. Paul P. Dobesh. Managing hypertension in patients with type 2 diabetes mellitus. Am J Health Syst Pharm., 2006; 63(12): 1140 - 1149.

5. Rashed. AN, Neubert. A, Tomlin. S, Jackman. J, Alhamdan. H, AlShaikh. A, Attar. A, Aseeri. M, Wilton. L and Wong. IC. Epidemiology and potential associated risk factors of drug-related problems in hospitalised children in the United Kingdom and Saudi Arabia. Eur J Clin Pharmacol., 2012; 68(12): 1657 - 1666.

6. Mohan. V, Siddharth Shah and Banshi Saboo. Current Glycemic Status and Diabetes Related Complications Among Type 2 Diabetes Patients in India: Data from the A chieve Study. Suppl JAPI, 2013; 61: 12 - 15.

7. British National Formulary Joint Formulary Committee: British National Formulary. $60^{\text {th }}$ Ed. London: British Medical Association and Royal Pharmaceutical Society of Great Britain; 2010.

8. Standard treatment guidelines, a Manual for Medical Practitioners. Edition 2010. Published by: Tamil Nadu 
Health systems Project, Health and Family Welfare Department, Government of Tamil Nadu, Tamil Nadu, India.

9. Frank Petrak, Stephan Herpertz, Christian Albus, Axel Hirsch, Bernhard Kulzer and Johannes Kruse. Psychosocial Factors and Diabetes Mellitus: Evidencebased Treatment Guidelines. Current Diabetes Reviews, 2005; $1: 1-16$.

10. Morisky. DE, Green. LW and Levine. DM. Concurrent and predictive validity of a self-reported measure of medication adherence. Med Care. 1986; 24: 67 - 74 . 11. Naranjo. CA, Busto. U, Sellers. EM, Sandor. P, Ruiz. I, Roberts. EA, Janecek. E, Domecq. C and Greenblatt. DJ. A method for estimating the probability of adverse drug reactions. Clin Pharmacol Ther., 1981; 30(2): 239 -245$.
12. Population Reference Bureau; 2012 World Population Data Sheet. Washington DC, USA: USAID; 2012. 13. Global Diabetes community; http://www.diabetes.co.uk/global-diabetes/diabetes-in-india.html - Accessed on $01 / 12 / 12$.

14. Zaman Huri and Fun Wee. Drug Related Problems in Type 2 Diabetes Patients with Hypertension: A Cross-Sectional Retrospective Study. BMC Endocrine Disorders, 2013; 13: 2.

15. PCNE Classification scheme for Drug related problems; www.pcne.org/sig/drp/documents/ PCNE\%20classification\%20V5.01.pdf - Accessed on $01 / 12 / 2012$.

16. Bob W. van Roozendaal and Ines Krass. Development of an evidence-based checklist for the detection of drug related problems in type 2 diabetes. Pharm World Sci, 2009; 31: 580 - 595. 